Fourth International Conference on Sustainable Construction Materials and Technologies http://www.claisse.info/Proceedings.htm

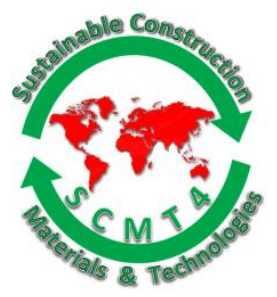

SCMT4

Las Vegas, USA, August 7-11, 2016

\title{
Compressive Behavior of Wheat Straw Reinforced Concrete for Pavement Applications
}

\author{
Muhammad Usman Farooqi ${ }^{1 a}$, and Majid Ali ${ }^{1 b}$ \\ ${ }^{I}$ Department of Civil Engineering; Capital University of Science and Technology - Islamabad, Pakistan. \\ ${ }^{1 a}$ Email: <m.usman@cust.edu.pk>; ${ }^{l b}$ Email:〈majid.ali@cust.edu.pk>.
}

\begin{abstract}
Conventional concrete pavements are frequently recommended because of their relatively long service life compared to flexible pavements. But micro shrinkage cracking is usually observed in normal concrete. This just leads to start of deterioration of pavement from the very early age, thus affecting its intended functionality. Fibre reinforced concrete can help in reducing the micro-cracking to a large extend. Many types of fibres (e.g. steel and artificial fibres) have already been investigated by many researchers for concrete pavements. To the best of author's knowledge, natural fibres are rarely studied for such applications. Natural fibres have been marvelous substitute to steel and artificial fibres for other applications. Keeping in mind this aspect of natural fibres, this pilot study is conducted to evaluate compressive behavior of wheat straw reinforced concrete for pavement applications. To study the influence of wheat straw in improving the properties of concrete, the properties of Plain Concrete (PC) are taken as reference. Mechanical properties i.e. compressive strength, corresponding strain modulus of elasticity, total energy absorbed and compressive toughness index are determined experimentally. Natural and treated wheat straws having lengths of approximately one inch and content of $3 \%$ by cement mass are considered. Thus, composites studied are Natural Wheat Straw Reinforced Concrete (NWSRC) and Treated Wheat Straw Reinforced Concrete (TWSRC). The proportions of cement, sand and aggregates are taken as $1,3.75$ and 1.75 , respectively. The reason for using more sand compared to aggregate is that more mortar is available for grabbing wheat straw. Water cement ratio for PC, NWSRC and TWSRC are taken as $0.50,0.60$, and 0.63, respectively. Discussions on mechanical properties of PC, NWSRC and TWSRC are made. During the testing, it was observed that the fragments of plain concrete were removed from cylinder specimens. On the other hand, only cracks were formed in wheat straw concrete cylinders. It is concluded that, due to bridging behavior, wheat straw reinforced concrete has the potential to be used for concrete pavement applications.
\end{abstract}

\section{INTRODUCTION}

Researchers have used natural fibres in concrete for various applications as an alternative replacement of steel or artificial fibres. Different natural fibres used in civil engineering applications include coir, sisal, sugarcane, banana, bamboo, malva, date, vakka, kenaf bast, jute, palm, hemp, pineapple leaf, flax, ramie bast, abbaca leaf, hibiscus cannabinus, and sansevieria leaf (Paramasivam et al., 1984; Satyanarayana et al., 1990; Agopyan et al., 2005; Toledo-Filho et al., 2005; Li et al., 2007; Munawar et al., 2007). Use of natural fibres can lead to have sustainable development (Ramakrishna and Sundararajan, 2005). Natural 
fibres are cheap and locally available in abundance in many countries. Hence, its use as a construction material costs a very little, in fact almost nothing when compared with the total cost of composite. In this way, huge savings can be made by using natural fibres. The benefit of natural fibres over artificial fibres may also include the easy handling of fibres due to their flexibility. However, the durability of natural fibres remains the topic of interest for many researchers till today. Accordingly, durability of natural fibres in concrete has been determined experimentally after exposing it in different environmental and ageing conditions (Toledo Filho et al., 2000; Toledo Filho et al., 2003; Ramakrishna and Sundararajan, 2005; Li et al., 2006; Sivaraja et al., 2010). The environmental and ageing conditions include (i) alternate wetting and drying, (ii) immersion in water, saturated lime and sodium hydroxide solutions for specific period, (iii) immersion in water at specified temperature and for a specified period, and (iv) alternate freeze and thaw cycles. A considerable amount (i.e. 58.7\%) of residual strength of natural fibres in composites was observed (Toledo Filho et al., 2000). A number of solutions were proposed by various researchers to increase the durability of natural fibres (Toledo Filho et al., 2003; John et al., 2005; Sivaraja et al., 2010). Thus, the durability of natural fibres does not provide much hindrance for their use in civil engineering applications. But durability should be given proper consideration due to organic nature of fibres.

The incorporation of artificial/steel fibres in concrete composites are investigated by various researchers for concrete pavements (Ramakrishnan et al., 1989; Gupta et al., 2011; Salemi and Behfarnia, 2013; Rai and Joshi, 2014; Sinha et al., 2014; Kanalli et al., 2014; Kolase et al., 2015; Kumar et al., 2015). Ramakrishnan et al. (1989) determined the fresh concrete properties, static flexural strength, hardened concrete properties and pulse velocity. All these properties are studied for fibre reinforced concrete to evaluate its flexural behavior and toughness for concrete pavements. Four different fiber types (i.e., straight steel, polypropylene, corrugated steel and hooked-end steel) and four contents $(0.5,1.0,1.5$, and $2.0 \%$ by volume) were considered. Results showed an increase in static flexural strength (15\% to $129 \%$ ) and first-crack strength (15\% to 90\%). Gupta et al. (2011) used Polyester Fiber Reinforced Concrete (PFRC), with and without fly ash, for pavement applications. Compressive and flexural strength, reduced drying shrinkage, abrasion resistance and deflection test were determined to evaluate the durability and mechanical properties of PFRC. The range of fibre contents used was $0-1 \%$ at increments of $0.25 \%$. The optimum fiber content was $0.25 \%$, which was selected for its better flexural strength and abrasion resistance. Results showed that the abrasion resistance of optimum PFRC was higher by about $25 \%$ than that of reinforced concrete. Salemi and Behfarnia (2013) compared the frost resistance and mechanical properties of plain concrete, concrete with nano-particles and concrete with polypropylene fibers for pavement application. In this study, the specimens were subjected to cycles of freezing and thawing in water according to ASTM C666A. The percentages of polypropylene (PP) used were $0.1 \%$ and $0.2 \%$ (by volume of concrete). The percentages of nano-silica (NS) used were 3\%, 5\%, and 7\% (by weight of cementitious material). The percentages of nano-alumina used were $1 \%, 2 \%$, and $3 \%$ (by weight of cementitious material). Optimum content of NS in concrete came out to be 5\% in order to improve its compressive strength as much high as $30 \%$. This resulted in $84 \%$ reduction in deterioration of concrete after freezing and thawing cycles. The study concluded that concrete containing 5\% NS incorporating $0.2 \%$ PP fibers improved durability by $87 \%$ and showed most frost resistance upto $82 \%$. Kanalli et al. (2014) studied the effect of polypropylene fiber (varying ratio of dosage of $0.25 \%$ by volume from $0.25 \%$ to $1.25 \%$ ) in concrete pavement by testing its tensile strength, flexural strength and compressive strength. Fiber reinforced concrete exhibited an increase in 28 days flexural and compressive strength by about $6.4 \%$ and $21 \%$, respectively. There was also a reduction in drying shrinkage from $0.062 \%$ to $0.03 \%$. Furthermore, they also concluded that higher initial cost by $15-20 \%$ is counterbalanced by the reduction in maintenance and rehabilitation operations, making polypropylene fibre reinforced concrete cheaper than flexible pavement by $30-35 \%$. Thus, the above mentioned studies investigated concrete incorporating (i) steel/artificial fibres for improving its properties and (ii) flyash, nano-silica and/or nano-alumina to reduce cement cost for economy in concrete pavements. 
The results of natural fibre reinforced concrete (NFRC) are comparable with those of artificial fibre reinforced concrete (AFRC) and steel fibre reinforced concrete (SFRC) for many civil engineering applications (Toledo Filho et al., 1999; Fernandez JE., 2002; Ramakrishna and Sundararajan, 2005; Rai and Joshi, 2014). For concrete pavements, the natural fibres are investigated in a single study so far by Patel D and Patel V (2015). They investigated the sugarcane bagasse fibre reinforced concrete for rigid pavement. Three aspect ratios i.e. 30, $60 \& 90$ were used with the fibre contents of $0.5 \%, 1 \%$, and $1.5 \%$ (by weight of concrete). The optimum aspect ratio and content came out to be 90 and $1 \%$, respectively. At this optimized material, an increase of $9 \%$ in compressive strength and $6 \%$ in flexural strength of concrete was observed. To the best of author's knowledge, no study has been reported on use of wheat straw reinforced concrete for pavement applications. However, Merta et al., (2011) studied wheat straw reinforced concrete for building material applications. They concluded that there is an increase (i.e. 2\%) in fracture energy of wheat straw reinforced concrete. Thus, wheat straw reinforced concrete needs to be investigated for rigid pavements. The current study is an initiative step to fill this knowledge gap.

The overall aim of the research program is the economic and long term improvement of rigid pavements by using locally available natural fibres in concrete. Wheat straw has been selected to start with. The reason for using wheat straw is it's cheap, local and abundant availability. The major part of goal can be achieved by investigating (i) optimization of materials for mix proportion, water - cement ratio and contents of fibres for wheat straw reinforced concrete, (ii) durability of wheat straws in concrete over a certain period for different environmental conditions, and (iii) applications of optimized wheat straw reinforced concrete for rigid pavements through pavement testing. In this kick-off work, comparative study of low strength Plain Concrete (PC), Natural Wheat Straw Reinforced Concrete (NWSRC) and Treated Wheat Straw Concrete (TWSRC) is made. Low strength wheat straw reinforced concrete can be used in parking pavements, footpaths and shoulders/cycle lane in pavements to avoid shrinkage cracking. It can also be used for the rigid pavements in residential colonies for light weight vehicles.

\section{EXPERIMENTAL INVESTIGATION}

Materials. Ordinary Portland cement, locally available sand, aggregates, potable water and wheat straws were used. Wheat straws, extracted from agricultural residues, were obtained from near-by source.

\section{Preparation of wheat straws}

Natural wheat straws. Locally available wheat straws were dipped in water for $15-20$ minutes. The purpose of dipping was to remove the dust from surface of straw. After that, straws were air dried. The lengths of straws are approximately one inch. These prepared straws are named as natural wheat straws (Figure 1a).

Treated wheat straws. In most of the practical situations, it is difficult to have an adequate interfacial bond sterngth with raw natural fibres. Different researchers have adopted various approaches to increase the bond strength with surrounding matrix by improving the fibre surfaces. This pretreatment requires the chemical and physical modifications of fibre surface (Ramaswamy HS et al., 1983; Mani and Satyanarayana, 1990; Aggarwal LK, 1992; Jianxin L, 1994; Ray D et al., 2001; Yan L et al., 2005; Brahmakumar M et al., 2005; Asasutjarita C et al., 2007; Gu H, 2009; Nirmal U et al., 2011). For this current work, a simple pre-treatment was used as done by Ali and Chouw (2009). Dry straws were dipped in boiling wáter. Water along with straws were kept on boiling for 2 hours. Hot straws were cooled and then air surface dried. These prepared straws are named as treated wheat straws (Figure 1b). 




(a)

(b)

Figure 1. Wheat Straws (a) Natural and (b) Treated

Mix proportions and casting procedure. For the plain concrete, the mix design ratio for cement, sand and aggregate was $1,3.75$ and 1.75 , respectively, with a water-cement ratio of 0.50 . Mix design for wheat straw reinforced concrete was same as that of plain concrete except that approximately one inch long wheat straws of $3 \%$ by mass of cement were added. Natural and treated wheat straws were used for preparing of wheat straw reinforced concrete.

Drum type concrete mixer was used in preparing concrete. For plain concrete, all materials were put in drum along with water, and mixer was rotated for three minutes. Slump test was performed before pouring concrete in moulds and the value of slump was 2-inches. For preparing wheat straw reinforced concrete, a different approach was adopted to avoid the collection of straws in jaws of mixer drum. The materials were put in drum in three layers. In first layer, one third of aggregates were spread in the drum followed by a layer of cement, straws and sand. The layer of straws was completely sandwiched between cement and sand layers by proper spreading. The same procedure was adopted for the remaining material. The three - fourth of water (according to water - cement ratio 0.50 as used for PC mix) was added at the end. The mixer was rotated for 2 minutes. The mixer was stopped then and remaining water was added. The mixer was rotated again for 1 minute. It was observed that wheat straw reinforced concrete was not workable at that stage. Therefore to make wheat straw reinforced concrete workable, more water was added in small increments with one minute rotation after each increment. In this way, the water - cement ratio came out to be 0.60 and 0.63 for NWSRC and TWSRC, respectively (Figure 2c). Slump test for NWRSC and TWRC was also performed in the same manner as performed for that of PC. The slump values for NWSRC and TWSRC were 1/8-inches and 7/8 -inches, respectively (Figure 2a \& 2b). The reason for more slump value of TWSRC may be due to the higher water - cement ratio. The values of slump along with water-cement ratios are shown in Table 1. The cylindrical moulds were filled in three layers with 25 blows of tamping rod after filling of each layer. In addition, for wheat straw reinforced concrete, the mould was lifted up to height of $4-6$ inches and then dropped freely on floor for proper compaction. The finish surfaces of wheat straw reinforced concrete cylinders were not smoother as compared to that of PC cylinders. This was due to the presence of wheat straws. All specimens were cured for 28 days before testing. 


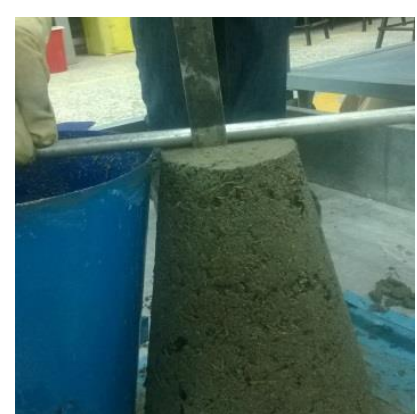

(a)

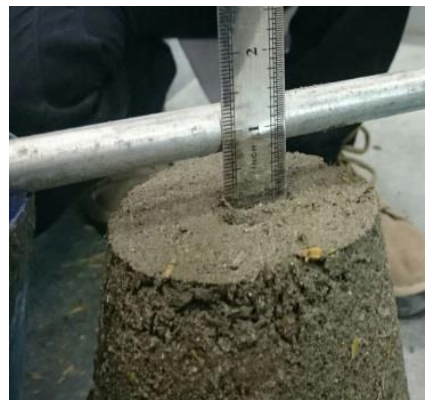

(b)

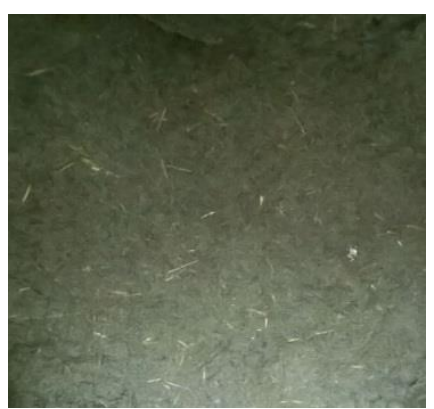

(c)

Figure2. Slump test (a) NWSRC, (b) TWSRC, and (c) Wet wheat straw reinforced concrete Table1. Water-Cement ratios and Slump of PC, NWSRC and TWSRC

\begin{tabular}{|c|c|c|}
\hline \multirow{2}{*}{ Specimen } & W/C Ratio & Slump \\
\cline { 2 - 3 } & - & (Inches) \\
\hline PC & 0.50 & 2 \\
\hline NWSRC & 0.60 & 0.125 \\
\hline TWSRC & 0.63 & 0.875 \\
\hline
\end{tabular}

Specimens. Cylinders with the dimensions of 4-in diameter and 8-in height were prepared for PC, NWSRC and TWSRC. Labels PCC, $\mathrm{N}$ and $\mathrm{T}$ are used for PC, NWSRC and TWSRC, respectively. Numeric figures along with labels show the number of sample for each specimen.

Testing procedure. All cylinders were tested in compression testing machine for compressive strength, corresponding strain modulus of elasticity, total energy absorbed and compressive toughness index. All cylinders were capped with sulphur for uniform distribution of load before testing. The cylinders were tested according to ASTM C39.

\section{RESULTS AND DISCUSSIONS}

Compressive strength 6 and corresponding strain $\epsilon_{0}$. Typical stress - strain curves for PC, NWSRC, and TWSRC are shown in Figure 3. The ascending side of stress - strain curve for PC is much steeper as compared to that of both NWSRC and TWSRC. In case of PC, a sudden failure was occurred as soon as the maximum load level is reached, showing its brittle behavior as expected. On the other hand, cracking was observed at maximum load for both NWSRC and TWSRC, showing their ductile nature. The maximum value of stress in stress - strain curve is taken as compressive strength (Table 2). There is a decrease in compressive strengths of both NWSRC and TWSRC as compared to that of PC. This decrease in compressive strength is usually observed when natural fibres are incorporated in concrete as also indicated by other researchers (Cook and Chindaprasirt, 1980; Ramaswamy et al., 1983; Ismail MA, 2007; Ali et al., 2012). The compressive strength of TWSRC is further less than that of NWSRC. However, the corresponding strain of TWSRC is more than that of both PC and NWSRC (Table 2). It may 
be because of changed chemical composition of wheat straws due to boiling. Crushed cylinder specimens are shown in Figure 5. During testing, PC fragments were separated from the cylinder as can be seen at the bottom right corner of cylinder in Figure 5a. While in fibre reinforced concrete cylinders, there was a bridging behavior due to the presence of wheat straws.

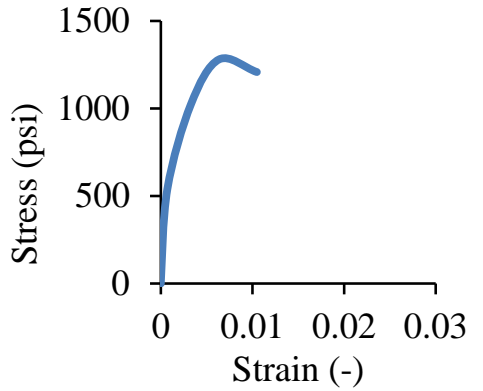

(a)

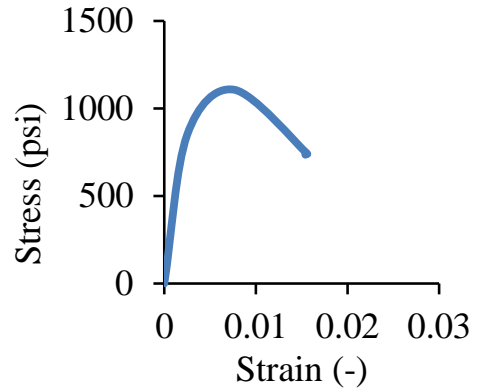

(b)

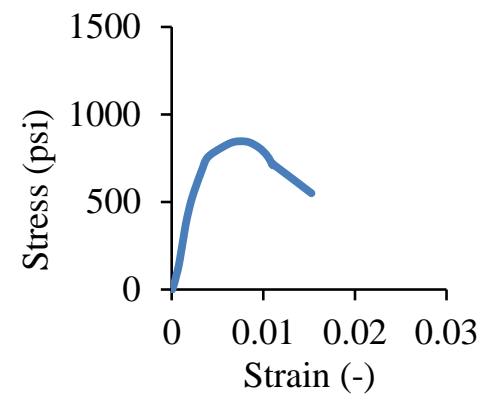

(c)

Figure 4. Typical Stress-strain curves for (a) PC, (b) NWSRC, \& (c) TWSRC

Table 2. Compressive Strength, Corresponding Strain and Modulus of Elasticity of PC, NWSRC and TWSRC

\begin{tabular}{|c|c|c|c|}
\hline \multirow{2}{*}{ Specimen } & $\begin{array}{c}\text { Compressive } \\
\text { Strength }(\mathbf{6})\end{array}$ & $\begin{array}{c}\text { Corresponding } \\
\text { Strain }\left(\boldsymbol{\epsilon}_{\mathbf{o}}\right)\end{array}$ & $\begin{array}{c}\text { Elastic Modulus } \\
(\mathbf{E})\end{array}$ \\
\cline { 2 - 4 } & $\mathbf{( p s i )}$ & - & $\mathbf{( k s i )}$ \\
\hline PC & 1112 & 0.006 & 332 \\
\hline NWSRC & 1008 & 0.007 & 339 \\
\hline TWSRC & 823 & 0.008 & 230 \\
\hline
\end{tabular}

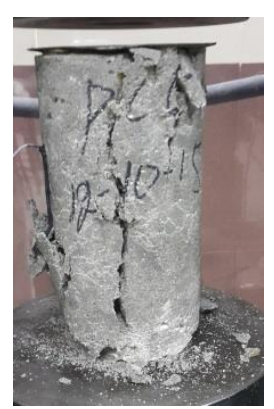

(a)

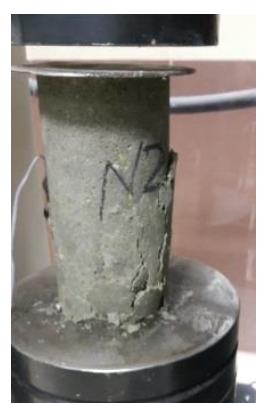

(b)

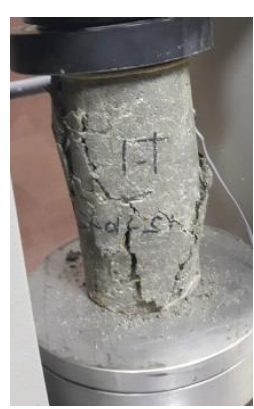

(c)

Figure 5. Tested cylinder specimens of (a) PC, (b) NWSRC, \& (c) TWSRC

Elastic Modulus 'E'. Elastic Modulus is calculated as the ratio of stress to strain change in the elastic range. Modulus of elasticity of PC, NWSRC and TWSRC is given in last column of Table 2. The elastic modulus is slightly increased in NWSRC and significantly decreased in TWSRC as compared to that of PC. The reduction might be due to (i) decrease in compressive strength of 
TWSRC and (ii) more deformation in the elastic range because of changed chemical composition of treated wheat straws. Similar behavior was observed by other researchers (Gupta et al., 2011; Rai et al., 2014; Sinha et al., 2014).

Total absorbed energy ' $e$ ' and Compressive toughness index 'CTI'. Total energy absorbed (e) is calculated as the area under stress - strain curve. Some researchers have taken it as compressive toughness (Mindess and Zhang, 2009; Ali et al. 2012). The area under stress - strain curve up to maximum stress is taken as energy absorbed up to maximum stress $\left(\mathrm{e}_{\mathrm{m}}\right)$. Whereas, the area under stress - strain curve from the maximum stress to maximum strain is taken as energy absorbed after maximum stress $\left(\mathrm{e}_{\mathrm{p}}\right)$. Compressive toughness index (CTI) is the ratio of total energy absorbed to the energy absorbed up to the maximum stress. The values of $\mathrm{e}_{\mathrm{m}}, \mathrm{e}_{\mathrm{p}}$, e and CTI are shown in Table 3. The total energy absorbed by NWSRC is higher (i.e. 22\%) than that of PC. The elongated deformation of NWSRC became the reason of more energy absorption. However, as stated earlier, Merta et al. (the only study on wheat straw reinforced concrete) observed only $2 \%$ increase in its fracture energy compared to that of plain concrete. If $e_{m}$ and $e_{p}$ of NWSRC are compared, more energy is absorbed after the maximum stress i.e. the significant cracking is started. Although the compressive toughness index for PC and TWSRC are same, but TWSRC specimen showed the bridged behavior and the fragments of PC specimen were broken during testing. The ductile nature of natural fibre reinforced composites was also reported in many studies (Yipp et al., 1998; Li et al., 2006; Ali et al., 2012).

Table 3. Total Absorbed Energy \& Compressive Toughness Index of PC, NWSRC and TWSRC

\begin{tabular}{|c|c|c|c|c|}
\hline \multirow{2}{*}{ Specimen } & $\begin{array}{c}\text { Energy up to } \\
\text { max stress }\end{array}$ & $\begin{array}{c}\text { Energy after } \\
\text { max stress }\end{array}$ & $\begin{array}{c}\text { Total Absorbed } \\
\text { Energy }\end{array}$ & CTI \\
\cline { 2 - 5 } & $\left(\mathbf{e}_{\mathbf{m}}\right)$ & $\left(\mathbf{e}_{\mathbf{p}}\right)$ & $\mathbf{e}=\left(\mathbf{e}_{\mathbf{m}}+\mathbf{e}_{\mathbf{p}}\right)$ & $\left(\mathbf{e} / \mathbf{e}_{\mathbf{m}}\right)$ \\
\cline { 2 - 5 } & $(\mathbf{p s i})$ & $(\mathbf{p s i})$ & $(\mathbf{p s i})$ & - \\
\hline PC & 5.7 & 5.5 & 10.9 & 1.9 \\
\hline NWSRC & 6.1 & 7.2 & 13.3 & 2.2 \\
\hline TWSRC & 5.2 & 4.9 & 10.1 & 1.9 \\
\hline
\end{tabular}

Density. Densities of PC, NWSRC and TWSRC are shown in Table 4. A decrease in density of both NWSRC and TWSRC is observed when compared to the density of PC. It is due to the presence of low-density straws. The same behavior was observed by the other researchers (Mannan and Ganapathy, 2004; Asasutjarita et al., 2007; Ismail MA, 2007; Ali et al., 2012).

Table 4. Density of PC, NWSRC and TWRSC

\begin{tabular}{|c|c|c|c|}
\hline \multirow{2}{*}{ Specimen } & \multicolumn{3}{|c|}{ Density (pcf) } \\
\cline { 2 - 3 } & \multicolumn{2}{|c|}{ Sample number } & \multirow{2}{*}{ Average } \\
\cline { 2 - 3 } & $\mathbf{1}$ & $\mathbf{2}$ & 139.75 \\
\hline PC & 138.42 & 141.07 & 135.23 \\
\hline NWSRC & 136.12 & 134.34 & 137.85 \\
\hline TWSRC & 136.64 & 139.07 & \\
\hline
\end{tabular}




\section{CONCLUSION}

Compressive behavior and densities of Plain Concrete (PC), Natural Wheat Straw Reinforced Concrete (NWSRC) and Treated Wheat Straw Reinforced Concrete (TWSRC) are investigated for possible applications in rigid pavements. Following conclusions are made on the basis of conducted study:

- Compressive strength of NWSRC is decreased by $10 \%$ as compared to PC. In case of TWRSC, the reduction is $26 \%$.

- The elastic modulus of NWSRC is increased by $3 \%$ and the elastic modulus of TWSRC is decreased by $32 \%$ compared to that of PC.

- There is an increase of $22 \%$ in total energy absorption by NWSRC as compared to that of PC. Almost $54 \%$ of total energy is being absorbed after the maximum stress by NWSRC.

- The compressive toughness index is increased for NWSRC by $14 \%$, whereas it remained same for TWSRC when compared to that of PC. Both NWSRC and TWSRC showed bridged behavior whereas PC showed brittle behavior.

- The densities of NWSRC and TWSRC are decreased by $4.5 \mathrm{pcf}$ and $1.9 \mathrm{pcf}$, respectively, when compared to the density of PC.

So it is concluded that wheat straw reinforced concrete has the potential to be used for the concrete pavement applications due to its post cracking behavior as it can elongate the period from the first crack up to the complete deterioration i.e. permanent failure.

Being a pilot study, the results discussed here are based on limited testing and analysis. The outcome seems favorable which demands for a detailed investigation. Therefore, studies focusing on optimization of contents of wheat straw reinforced concrete, its durability and its application in rigid pavements are recommended.

\section{ACKNOWLEDGEMENTS}

The authors would like to thank all persons/organizations who helped them throughout the research, particularly Asif Jalal and Muhammad Junaid for their kind help during lab work.

\section{REFERENCES}

Aggarwal, LK. (1992). "Studies on Cement-Bonded Coir Fibre Boards." Cement Concrete Compos, 14(1), 63-69.

Agopyan, V., Savastanojr, H., John, V. and Cincotto, M. (2005). "Developments on Vegetable FibreCement based Materials in Sau Paulo, Brazil: An Overview." Cement Concrete Compos, 27(5), 527536.

Asasutjarita, C., Hirunlabha, J., Khedarid, J., Charoenvaia, S., Zeghmatib, B. and Cheul, Shin, U. (2007). "Development of Coconut Coir-based Lightweight Cement Board." Construction Building Materials, 21(2), 277-288.

Ali, M., Li, X. and Chouw, N. (2012). " Mechanical and Dynamic properties of Coconut Fibre Reinforced Concrete." Construction Building Materials, 21(2), 277-288.

Ali, M. and Chouw, N. (2009). "Dynamic Testing of Coir Fibre Reinforced Concrete Beam." 8th Int. conf. on SILOS , Uni. of Adelaide, Australia, 137-144. 
Brahmakumar, M., Pavithran, C. and Pillai, RM. (2005). "Coconut Fibre Reinforced Polyethylene Composites: effect of natural waxy surface layer of the fibre on fibre-matrix interfacial bonding and strength of composites." Compos Sci Technol, 65, 563-9.

Cook, DJ. and Chindaprasirt P. (1980). "Influence of Loading History upon the Compressive properties of Concrete." Mag Conc Res, 89-100.

Fernandez, JE. (2002). "Flax Fibre Reinforced Concrete - A Natural Fibre Bio Composite for Sustainable Building Materials." High Performance Structures and Materials, C.A Brebbia and W.P. Wilde, Editors Seville, 193-207.

$\mathrm{Gu}, \mathrm{H}$. (2009). "Tensile Behaviors of the Coir Fibre and related Composites after $\mathrm{NaOH}$ Treatment." Mater Des, 30, 3931-4.

Gupta, S., Rao, V. and Sengupta, J. (2011). "Evaluation of Polyester Fiber Reinforced Concrete for Use in Cement Concrete Pavement Works." Road Materials and Pavement Design,9(3), 441-461.

Ismail, M.A. (2007). "Compressive and Tensile Strength of Natural Fibre-reinforced Cement base Composites." Al-Rafdain Engineering, 15(2), 42-51.

Jianxin. L. (1994). "Analysis of the pull-out of Single Fibres from Low-Density Polyethylene." Canada, M5S 1A4: Dept. of Chemical Engg and Applied Chemistry, University of Toronto.

John, VM., Cincotto, C., Agopyan, V. and Oliveira, CTA. (2005). "Durability of Slag Mortar reinforced with Coconut fibre." Cement Concrete Composites, 27(5), 565-74.

Kanalli, S.A., Palankar, R., Kumar. B., Kumar, P. and Prakash, S.K. (2014). "Comparative Study of Polypropylene Fiber-Reinforced Concrete with Conventional Concrete Pavement." International Journal of Research in Engineering and Technology, 03(01), 139-143.

Kumar, P.R., Vijaybaskaran, S., PrasannaVenkatesh, R., Saravannamoorthy S.V. and Srinath, M. (2015). "Effect of Steel and Polypropylene Fibres on the Strength Characteristics of a Cement Concrete Overlay." International Journal of ChemTech Research, 6(8), 621-627.

Li, Z., Wang, L. and Wang, X. (2006). "Flexural Characteristics of Coir Fibre Reinforced Cementitious Composites." Fibres Polymers, 7(3), 286-294.

Li, Z. and Wang, X. (2007). "Cement Composites Reinforced with Surface Modified Coir Fibres." Composite Material Journal, 41(12), 1445-1457.

Mani, P. and Satyanarayana, KG. (1990). "Effects of the Surface Treatments of Lingo-cellulosic Fibres on their Debonding Stress." J Adhes Sci Technol, 4(1), 17-24.

Mannan, M.A. and Ganapathy, C. (2004). "Concrete from an agricultural waste oil palm shell (OPS)." Building and Environment, 39(4), 441-448.

Merta, I., Tschegg, E.K., Stanzl-Tschegg, S.E. and Kolbitsch, A. (2011). "Fracture Mechanics of Concrete Reinforced with Hemp, Straw and Elephant grass Fibres." $18^{\text {th }}$ International Conference on Composite Materials.

Mindess, S. and Zhang, L. (2009). "Impact Resistance of Fibre Reinforced Concrete." In proceedings of the institution of civil engineers structures and buildings, SBI: 69-76 (Paper no.700063).

Munawar, SS. Umemura, K. and Kawai, S. (2007). "Characterization of the Morphological, Physical and Mechanical properties of seven Non-wood Plant Fibre Bundels.” Wood Science Journal, 53(2), 108113.

Nirmal, U., Singh, N., Hashim, J., Lau, STW. and Jamil, N. (2011). "On the Effect of different Polymer Matrix and Fibre Treatment on Single Fibre Pullout test using Betelnut Fibres." Mater Des, 32:2, 717 26. 
Paramasivam, P., Nathan, GK. And Das Gupta, NC. (1984). "Coconut Fibre Reinforced Corrugated Slabs Int.” Cement Composites Lightweight Concrete Journal, 6(1), 19-27.

Paramod, K.K., Desai, A.K., Shivamanth and Shrikant, R.B. (2015). "Steel Fiber Reinforced Concrete Pavement: A Review." International Journal for Innovative Research in Science \& Technology, 10(1), 275-276.

Patel, D. and Patel, V.M. (2015). "Application of Sugarcane Bagasse Fibres as Concrete Composites for Rigid Pavement." Indian Journal of Research, 4(4), 4-5.

Ramakrishna, G. and Sundarajan, T. (2005a). "Impact Strength of a Few Natural Fibre Reinforced Cement Mortar Slabs: A Comparative Study.” Cement Concrete Compos Journal, 27(5), 547-553.

Ramakrishna, G. and Sundarajan, T. (2005b). "Studies on the Durability of Natural Fibres and Effect of Corroded Fibres on the Strength of Mortar." Cement Concrete Composites, 27(5), 575-582.

Ramakrishnan, V., George, Y. and Girish, H. (1989). "Flexural Behavior and Toughness of Fiber Reinforced Concrete.” Transportation Research Board, 12(26), 69-77.

Ramaswamy, HS., Ahuja, BM. and Krishnamoorthy, S. (1983). "Behaviour of Concrete Reinforced with Jute, Coir and Bamboo fibres." Int J Cem Compos Lightweight Conc, 5(1), 3-13.

Ray, D., Sarkar, BK., Rana, AK. and Bose, NR. (2001). "Effect of Alkali-treated Jute Fibres on Composite properties." Bull Mater Sci, 24(2), 129-35.

Rai, A. and Joshi, Y.P. (2014). "Applications and Properties of Fibre Reinforced Concrete." Int. Journal of Engineering Research and Applications, 4(5), 123-131.

Satyanarayana, KG., Sukumaran, K., Mukherjee, PS., Pavithran, C. and Pillai, SGK. (1990). "Natural Fibre-polymer Composites." Cement Concrete Compos, 12(2), 117-136.

Salemi, N. and Behfarnia, K. (2013). "Effect of Nano-particles on Durability of Fiber-Reinforced Concrete Pavement." Construction and Building Materials, 48, 934-941.

Sinha, D., Mishra, C.B. and Solanki, R.V. (2014). "Comparison of Normal Concrete Pavement with Steel Fiber Reinforced Concrete Pavement." Indian Journal of Applied Research, 4(8), 233-235.

Siviraja, M., Kandasamy, Velmani, N. and Pillai MS. (2010). Study on Durability of Natural Fibre Concrete Composites using Mechanical strength and Microstructural properties." Bullet Master Science, 33(6), 719-29.

Toledo, Filho, RD., Kuruvilla, J., Khusrow, G. and George, LE. (1990). "The Use of Sisal Fibre Reinforcement in Cement Based Composites." R. Bras. Eng. Agric. Ambiental, 3(2), 245-256.

Toledo, Filho, RD., Scrivener, K., England, GL. and Ghavami, K. (2000). "Durability of Alkali Sensitive Sisal and Coconut fibres in Cement." Cement Concrete Compos, 22, 127-143.

Toledo, Filho, RD., Scrivener, K. and Ghavami, K. (2003). "Development of Vegetable Fibre Mortar Composites of Improved Durability”. Cement Concrete Res, 25, 185-196.

Toledo, Filho, RD., Khosrow, G., Sanjuan, MA. and George, LE. (2005). "Free Restrained and Drying Shrinkage of Cement Mortar Composites Reinforced with Vegetable Fibres." Cement Concrete Compos, 27(5), 537-546.

Yan, L., Mai, YW. and Te, L. (2005). "Effects of Fibres Surface Treatment on Fracture-mechanical properties of Sisal Fibre Composites." Compos Interfaces, 12(1-2), 141-63.

Yipp, M., Shin, F. and Xian, X. (1998). "Bamboo fibre and Coconut Husk fibre Reinforced Cement Composite Materials.” Acta Metall Sin, 15(3), 92-98. 